Revista Brasileira de Agricultura Irrigada v.13, nº.6, p. 3714 - 3723, 2019

ISSN 1982-7679 (On-line)

Fortaleza, CE, INOVAGRI - http://www.inovagri.org.br

DOI: $10.7127 /$ rbai.v13n6001137

Protocolo 1137.19 - 10/04/2020 Aprovado em 11/05/2020

\title{
DESEMPENHO PRODUTIVO DA SOJA COM IRRIGAÇÃO SUPLEMENTAR NOS TABULEIROS COSTEIROS DE ALAGOAS
}

José Wanderson Silva dos Santos ${ }^{1}$, Wemerson Saulo da Silva Barbosa ${ }^{2}$, Iêdo Peroba de Oliveira Teodoro $^{3}$, José Antonio Costa Silva ${ }^{4}$, Iêdo Teodoro ${ }^{5}$, Guilherme Bastos Lyra ${ }^{6}$

\begin{abstract}
RESUMO
A adaptabilidade de cultivares de soja (Glycine max (L.) Merr.) nos Tabuleiros Costeiros de Alagoas é uma opção para o cultivo de áreas anteriormente cultivadas com cana-de-açúcar. Por isso, o objetivo nesse trabalho foi determinar a produtividade e a eficiência no uso da água para produção de grãos e matéria seca de cultivares de soja, na região de Rio Largo, Alagoas. As cultivares utilizados foram: AS 3730, BMX-POTÊNCIA, BRS 9383, M 6210, M 8349 e M 6410, plantadas em blocos ao acaso e as variáveis estudadas foram: chuva, evapotranspiração da cultura, temperatura do ar, produtividade agrícola, matéria seca, eficiência no uso da água para produção de grãos. A evapotranspiração da cultura média foi $4,50 \mathrm{~mm}$ por dia. As cultivares AS 3730 e M 8349 apresentaram melhor desempenho com produtividade média de 5,31 t ha ${ }^{-1}$ (valor que representa $36,4 \%$ maior que a média nacional na safra 2017/2018) e eficiência no uso da água para produção de grãos com média de $1,10 \mathrm{~kg} \mathrm{~m}^{-3}$. As variedades BRS 9383 e M 8349 apresentam maior potencial de produção de matéria Seca, média 18,03 $\mathrm{t} \mathrm{ha}^{-1}$, fator que é diretamente ligado ao rendimento de grão e evapotranspiração da cultura. A cultivar M 8349 apresentou o melhor desempenho geral para as condições locais.
\end{abstract}

Palavras-chave: Matéria seca, cultivares, evapotranspiração da cultura.

\section{PRODUCTIVE PERFORMANCE OF SOYBEAN WITH SUPPLEMENTARY IRRIGATION IN COASTAL PLAINS OF ALAGOAS}

\footnotetext{
${ }^{1}$ Graduando em Agronomia, Universidade Federal de Alagoas, Centro de Engenharias e Ciências Agrárias, UFALCECA, BR-104, CEP: 57100-000, Rio Largo, Alagoas, Brasil. Fone: (82) 3261-1351. E-mail: jose.wanderson@ceca.ufal.br;

${ }^{2}$ Doutorando em Produção Vegetal, Laboratório de Irrigação e Agrometeorologia, UFAL/CECA, Rio Largo, Alagoas, Brasil. E-mail: agrowssb@gmail.com;

${ }^{3}$ Graduando em Agronomia, Laboratório de Irrigação e Agrometeorologia, UFAL/CECA, Rio Largo, Alagoas, Brasil. Email: iedo_peroba@hotmail.com;

${ }^{4}$ Graduando em Agronomia, Laboratório de Irrigação e Agrometeorologia, UFAL/CECA, Rio Largo, Alagoas, Brasil. Email: antoniocosta.s@hotmail.com;

${ }^{5}$ Professor Doutor, Laboratório de Irrigação e Agrometeorologia, UFAL/CECA, Rio Largo, Alagoas, Brasil. E-mail: iedoteodoro@gmail.com;

${ }^{6}$ Professor Doutor, Laboratório de Irrigação e Agrometeorologia, UFAL/CECA, Rio Largo, Alagoas, Brasil. E-mail: gbastolyra@gmail.com.
} 


\begin{abstract}
The adaptability of soybean cultivars (Glycine $\max (\mathrm{L}$.$) Merr.) in the Coastal Tableland of Alagoas is$ an option for the cultivation of areas previously cultivated with sugarcane. herefore, the objective of the work was to determine the productivity and the efficiency in the use of water for grain production and biomass of soybean cultivars, in the region of Rio Largo, AL. The cultivars used were: AS 3730, BMX-POWER, BRS 9383, M 6210, M 8349 and M 6410, planted in a randomized block and the variables studied were: rainfall, evapotranspiration of culture, air temperature, agricultural productivity, dry matter, water use efficiency for grain production. The mean evapotranspiration of culture was $4.50 \mathrm{~mm}$ per day. The cultivars AS 3730 and M 8349 showed better performance with an average yield of $5.31 \mathrm{t} \mathrm{ha}^{-1}$ (value that represents $36.4 \%$ higher than the national average in the $2017 / 2018$ harvest) and efficiency in the use of water for grain production with an average of $1.10 \mathrm{~kg}$ $\mathrm{m}^{-3}$. The varieties BRS 9383 and M 8349 have the highest potential for dry matter production, averaging $18.03 \mathrm{t} \mathrm{ha}^{-1}$, a factor that is directly linked to grain yield and crop evapotranspiration. The cultivar M 8349 showed the best overall performance for local conditions.
\end{abstract}

Keywords: Dry matter, cultivars, crop evapotranspiration.

\section{INTRODUÇÃO}

A produção de grãos é uma das opções para diversificação da agricultura alagoana, a exemplo da cultura da soja (Glycine max (L.) Merr.) que é a principal "commodity" do agronegócio brasileiro. A disponibilidade de água para as plantas é um dos fatores decisivos para a produção agrícola, principalmente para o cultivo de soja (RUVIARO et al., 2011) e a zona da mata alagoana possui características edafoclimáticas compatíveis com as demandas dessa leguminosa. A quantidade de água necessária para determinada cultura é uma informação básica que deve ser conhecido para o manejo adequado de qualquer projeto de irrigação. Isso possibilita o aumento da produção sem a necessidade de abertura de novas áreas (GAVA et al., 2015).

$\mathrm{Na}$ costa leste do Nordeste (NE) brasileiro, região climática em que se insere a zona canavieira alagoana, a estação seca acontece durante a primavera/verão e nesse período os plantios de soja irrigados devem ser mais produtivos e menos expostos a riscos climáticos do que no outono/inverno. Conforme Teodoro (2003), durante o outono/inverno na costa leste do NE brasileiro, geralmente, há grandes excessos de chuvas que podem causar estresses hídricos (por excesso) em lavouras de leguminosas, sobretudo em plantios de soja. Manosso (2005) constatou que as condições climáticas influenciam diretamente sobre a dinâmica do rendimento anual das safras agrícolas, inclusive é capaz de representar uma perda de $47 \%$ em relação à produtividade média de soja.

Além disso, quando o déficit se desenvolve de forma mais lenta, pode prejudicar o crescimento vegetativo (CHAVARIA et al., 2015) Os aspectos nutricionais e o potencial para produção de matéria seca de cultivares de soja, aliados com pacotes tecnológicos e a facilidades para colheita mecanizada nos Tabuleiros Costeiros de Alagoas, fazem com que essa cultura seja uma alternativa para a alimentação animal de elevada qualidade. As práticas culturais realizadas corretamente podem proporcionar uma redução nos custos referentes à alimentação dos animais, pois com a utilização de forragem de alta qualidade, pode-se diminuir o fornecimento de rações concentradas, que têm maiores custos (REZENDE et al., 2012).

A produção de matéria seca (MS) das plantas de soja é uma variável diretamente relacionada com o rendimento de grãos e a evapotranspiração da cultura (ETc). Além do mais, o conhecimento da ETc em uma determinada região é imprescindível para otimizar o manejo de irrigação e a produção 
agrícola. Deste sentido, o objetivo, nesse trabalho, foi analisar as variáveis agrometeorológicas (chuva, evapotranspiração da cultura e temperatura do ar), produtividade agrícola, matéria seca e a eficiência no uso da água de cultivares de soja em relação a produção de grãos.

\section{MATERIAL E MÉTODOS}

O experimento foi conduzido no Centro de Ciências Agrárias da Universidade Federal de Alagoas (CECA/UFAL), Rio Largo - AL (9²8'29,1'’S; 3549'43,6' 'W; Altitude: 127,0 m) numa área de $1.155 \mathrm{~m}^{2}$ (Figura 1).

$\mathrm{O}$ solo é classificado como Latossolo Amarelo coeso argissólico de textura média-argilosa (MORAIS et al., 2017). As médias climatológicas anuais (1972-2010) de precipitação pluvial, temperatura do ar média, umidade relativa média são $\quad 1789,5 \mathrm{~mm}, \quad 25,4 \quad{ }^{\circ} \mathrm{C}, \quad 81,8 \%$, respectivamente (FERREIRA JUNIOR et al., 2014).

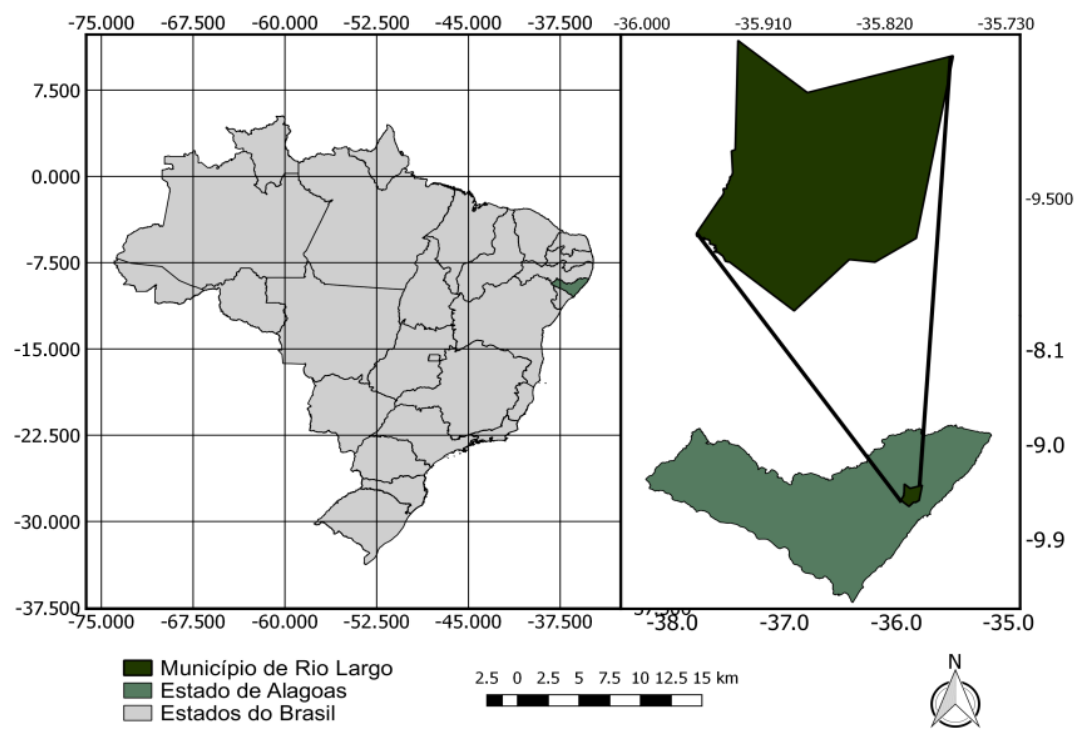

Fonte: Alpiano Neto (dados não publicados).

Figura 1. Localização da área experimental no município de Rio Largo - AL.

Antes da instalação do experimento, foi realizado a coleta da amostra do solo, nas profundidades de $0-0,2$ e 0,2 - 0,4 m para análise química (Tabela 1). Em seguida realizou-se o preparo de solo através de duas gradagens, a adubação de fundação foi determinada baseado na análise química e recomendação para a cultura da soja, de acordo com o manual técnico de Pernambuco (IPA, 2008), foram distribuídos $640 \mathrm{~kg} \mathrm{ha}^{-1} \mathrm{do}$ formulado 15-30-23, nível de 96, 192 e $147 \mathrm{~kg}$ ha $^{-1}$ de $\mathrm{N}, \mathrm{P}_{2} \mathrm{O}_{5}$ e $\mathrm{K}_{2} \mathrm{O}$. 
Tabela 1. Análise química do solo da área experimental do CECA/UFAL, antes da instalação do experimento com soja, Rio Largo - AL, outubro de 2018

\begin{tabular}{|c|c|c|c|c|c|c|c|c|c|}
\hline \multirow{2}{*}{$\begin{array}{c}{ }^{1} \text { Prof. } \\
\text { m }\end{array}$} & \multirow{2}{*}{$\begin{array}{c}\mathrm{pH} \\
\mathrm{H}_{2} \mathrm{O}\end{array}$} & $\mathrm{P}$ & $\mathrm{K}$ & $\mathrm{Na}$ & $\mathrm{Ca}$ & $\mathrm{Mg}$ & $\mathrm{Al}$ & $\mathrm{H}+\mathrm{Al}$ & ${ }^{2} \mathrm{CTC}_{\mathrm{t}}$ \\
\hline & & \multicolumn{3}{|c|}{---mg dm-3 ---- } & \multicolumn{5}{|c|}{ 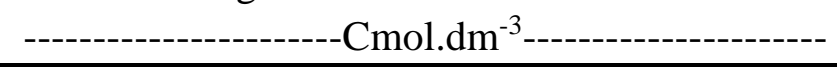 } \\
\hline $0-0,2$ & 5,5 & 3 & 20 & 10 & 1,89 & 1,23 & 0,09 & 4,66 & 3,3 \\
\hline $0,2-0,4$ & 6,1 & 4 & 25 & 10 & 2,5 & 1,89 & 0 & 3,12 & 4,49 \\
\hline Prof. & ${ }^{3} \mathrm{CTC}_{\mathrm{T}}$ & MO & ${ }^{4} \mathrm{~V}$ & ${ }^{5} \mathrm{~m}$ & $\begin{array}{c}\text { Sat. } \\
\mathrm{Ca}\end{array}$ & Sat. $\mathrm{Mg}$ & Sat. K & Sat. Na & - \\
\hline $\mathrm{m}$ & Cmol.dm ${ }^{-3}$ & $\mathrm{~g} \mathrm{~kg}^{-1}$ & $\ldots$ & - & 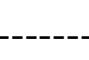 & -----\% & & ------" & - \\
\hline $0-0,2$ & 7,87 & 26,3 & 41 & 3 & 24 & 15,6 & 0,6 & 0,5 & - \\
\hline $0,2-0,4$ & 7,61 & 29 & 59 & 0 & 32.9 & 24,8 & 0,8 & 0,5 & - \\
\hline
\end{tabular}

${ }^{1}$ Profundidade (Prof.); Capacidade de troca de cátions efetiva (CTCt); Capacidade de troca de cátions total $\left(\mathrm{CTC}_{\mathrm{T}}\right.$ ); ${ }^{4}$ Saturação por bases (V); ${ }^{5}$ Saturação por alumínio (m).

Foram utilizadas as cultivares AS 3730, BMX-POTÊNCIA, BRS 9383, M 6210, M 8349 e M 6410 que apresentam alto potencial agronômico e diferentes grupos de maturação relativo (GM), conforme descritas na Tabela 2 (STÜLP et al., 2009). A implantação do experimento foi realizada em uma área de 0,12 ha, o delineamento estatístico foi bloco ao acaso, com cinco repetições e o total de trinta parcelas, cada parcela é formada por dez linhas de $5 \mathrm{~m}$ de comprimento, espaçados à $0,5 \mathrm{~m}$.
De acordo com Cruz et al., (2016) foi utilizado a população de 350.000 plantas por hectares.

O plantio foi realizado no dia 14 de novembro de 2018 e colheita no dia 18 de março de 2019 para as cultivares AS 3730, BMX-POTÊNCIA, M 6210, M 8349 e M 6410 a colheita da cultivar BRS 9383 foi no dia 03 de abril de 2019. Época de plantio semelhante as descritas em trabalhos anteriores por Zanon et al., 2015; Tretin et al., 2013.

Tabela 2. Características das cultivares de soja utilizadas no experimento, no período de 14 de novembro de 2018 a 18 de março de 2019, na região de Rio Largo - AL.

\begin{tabular}{cccc}
\hline Cultivar & Grupo de maturação & Hábito de crescimento & Evento tecnológico \\
\hline AS 3730 & 7.3 & Indeterminado & Intacta RR2 PRO \\
BMX-POTÊNCIA & 6.7 & Indeterminado & Roundup Ready 2 \\
BRS 9383 & 9.3 & Determinado & Roundup Ready 2 \\
M 6210 & 6.2 & Indeterminado & Intacta RR2 PRO \\
M 6410 & 6.4 & Indeterminado & Intacta RR2 PRO \\
M 8349 & 8.3 & Determinado & Intacta RR2 PRO \\
\hline
\end{tabular}

Os dados de rendimento agronômico foram coletados na área útil $\left(4 \mathrm{~m}^{2}\right)$ de cada parcela e as variáveis estudadas foram: produtividade agrícola (PA), matéria seca (MS) e eficiência no uso da água para produção grãos (EUAG). O manejo de plantas daninhas foi efetuado em pré-emergência (Flumioxazina $500 \mathrm{~g} \quad \mathrm{~L}^{-1}$ ) e em pósemergência (glifosato $\mathrm{N}$-(fosfonometil) glicina
- $370 \mathrm{~g} \mathrm{~L}^{-1}+$ Glifosato $\left.445 \mathrm{~g} \mathrm{~L}^{-1}\right)$. O controle de pragas foi realizado com a aplicação de inseticidas (Imidacloprido $700 \mathrm{~g} \mathrm{~kg}^{-1}$ ) e (Lambda - cialotrina $50 \mathrm{~g} \mathrm{~L}^{-1}$ ). O fungicida (Tebuconazol $200 \mathrm{~g} \mathrm{~L}^{-1}+$ Trifloxistrobina 100 $\mathrm{g} \mathrm{L}^{-1}$ ) foi utilizado como forma de prevenção contra doenças fúngicas (AGROFIT, 2018).

As variáveis meteorológicas (ETo, chuva e temperatura média do ar) foram 
cedidas pelo Laboratório de Irrigação e Agrometeorologia (LIA) do CECA/UFAL, que possui uma estação agrometeorológica automática ao lado da área experimental. A irrigação foi realizada por meio do sistema por aspersão convencional, com aspersores espaçados a 12 x $12 \mathrm{~m}$, a quantidade de água aplicada foi determinada baseado na evapotranspiração da cultura - ETc, obtido pela equação 1 .

A eficiência no uso da água para produção de grãos $\left(\mathrm{kg} \mathrm{m}^{-3}\right)$ é calculada através da equação 2 .

$\mathrm{ETc}=\mathrm{ETo} * \mathrm{kc}$

Em que: ETc - evapotranspiração da cultura, $\left(\mathrm{mm} \mathrm{dia}{ }^{-1}\right)$; ETo - evapotranspiração de referência, $\left(\mathrm{mm} \mathrm{dia}^{-1}\right)$ e coeficiente da cultura - kc (ALLEN et al., 1998).

EUAG $=\frac{\text { ETc total }}{\text { produtividade }}$

Em que: EUAG - eficiência no uso da água para produção de grãos, $\left(\mathrm{kg} \mathrm{m}^{-3}\right)$; ETc total evapotranspiração da cultura total do ciclo de cultivo, $(\mathrm{mm})$ e PA - produtividade agrícola $(\mathrm{t}$ $\left.\mathrm{ha}^{-1}\right)$.

A PA foi obtida através da massa seca dos grãos (13\% umidade), mediante a pesagem e expressa em quilogramas por hectare (Equação 3). A MS (t ha ${ }^{-1}$ ) foi obtida por pesagem em balança de precisão após a secagem das plantas em estufa de circulação de ar forçada a $65^{\circ} \mathrm{C}$ por 72 horas.
$P A=\left(\frac{Y}{C * E}\right) * 10.000$

Em que: PA - produtividade agrícola $\left(\mathrm{t} \mathrm{ha}^{-1}\right)$; $\mathrm{Y}$ - massa de grãos colhidos na área amostrada (kg); C - comprimento das linhas colhidas (m) e E - o espaçamento entre linhas (m).

Os dados de PA, MS e EUAG foram submetidos à testes de normalidade para verificar a aplicabilidade da ANOVA, seguida do teste de comparação de média de Tukey.

\section{RESULTADOS E DISCUSSÃO}

A Evapotranspiração da cultura, nos 106 dias de cultivo, no período de 14 de novembro de 2018 a 28 de fevereiro de 2019, variou entre $1,71 \mathrm{~mm}$ no dia 17 de fevereiro de 2019 e 7,20 $\mathrm{mm} \mathrm{dia}^{-1}$ no dia 30 de dezembro de 2018, média de $4,50 \mathrm{~mm} \mathrm{dia}{ }^{-1}$. Nesse mesmo período choveu $234,80 \mathrm{~mm}$ e ETc total foi 481 $\mathrm{mm}$, por isso foram aplicados $345,82 \mathrm{~mm}$ de irrigação. Portanto, não houve deficiência hídrica porque a chuva mais irrigação totalizaram 589,62 $\mathrm{mm}$, de modo que ainda ocorreu excesso hídrico por conta das chuvas de 36 e $29 \mathrm{~mm}$ (Figura 2), ocorridas nos dias 17 de dezembro de 2018 e 28 de janeiro de 2019, respectivamente.

A demanda hídrica da soja ficou dentro da faixa ideal SEDIYAMA, 2015 que varia de 450 a $850 \mathrm{~mm}$. A temperatura do ar, oscilou entre 22,0 e $30,5{ }^{\circ} \mathrm{C}$ (Figura 2), média de $25,7^{\circ} \mathrm{C}$. A temperatura média do ar está dentro das condições favoráveis entre 20 e $30{ }^{\circ} \mathrm{C}$, isso significa que as condições térmicas são adequadas para o crescimento e desenvolvimento da soja (BATTISTI; SENTELHAS, 2014). 


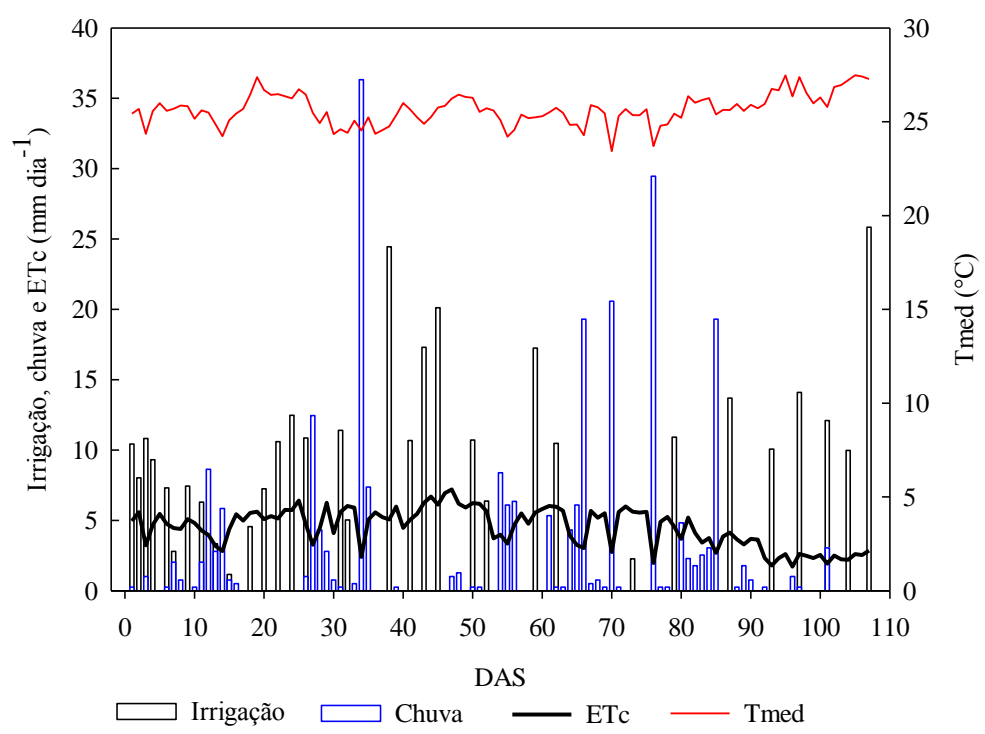

Figura 2. Irrigação, precipitação pluvial (chuva), evapotranspiração da cultura $\left(\mathrm{ET}_{\mathrm{c})}\right.$ e temperatura média do ar (Tmed) em relação aos dias após a semeadura (DAS), no período de 14 de novembro de 2018 a 28 de fevereiro de 2019, na região de Rio Largo - AL.

O excesso hídrico total de 108,62 mm, não foi prejudicial para o cultivo da soja, isso relaciona-se com resultados obtidos por Gava et al., (2016), verificaram que se pode aplicar lâminas de até $150 \%$ da ETc, para o tipo de solo utilizado, que o excesso hídrico não causou prejuízos. Fernandes e Turco (2003) constataram que os maiores valores de ETc ocorreram no período compreendido entre o início do florescimento até o enchimento de grãos. Outra fase crítica em relação a demanda hídrica é a emergência, por requisitar um bom nível de umidade do solo para garantir a uniformidade do estande. A produtividade agrícola, matéria seca e a eficiência no uso da água das cultivares de soja apresentaram efeito significativo $(P<0,01)$ para as cultivares analisadas (Tabela 3). Observa-se que todas as variáveis analisadas foram influenciadas significativamente pelos tratamentos testados.

Tabela 3. Análise de variância (Quadro médio) para os componentes de produção: produtividade agrícola - PA $\left(\mathrm{t} \mathrm{ha}^{-1}\right)$ e matéria seca - $\mathrm{MS}\left(\mathrm{t} \mathrm{ha}^{-1}\right)$ e eficiência no uso da água para produção de grão EUAG $\left(\mathrm{kg} \mathrm{m}^{-3}\right)$ de cultivares de soja irrigado no período de 14 de novembro de 2018 a 18 de março de 2019, na região de Rio Largo - AL.

\begin{tabular}{ccccc}
\hline \multirow{2}{*}{ Variáveis } & \multirow{2}{*}{$\mathrm{GL}^{1}$} & \multicolumn{3}{c}{ Quadrado Médio } \\
\cline { 3 - 5 } & & $\mathrm{PA}\left(\mathrm{t} \mathrm{ha}^{-1}\right)$ & $\mathrm{MS}\left(\mathrm{t} \mathrm{ha}^{-1}\right)$ & EUAG $\left(\mathrm{kg} \mathrm{m}^{-3}\right)$ \\
\hline Cultivares $(\mathrm{C})$ & 5 & $3292840,52^{* *}$ & $114846369,71^{* *}$ & $0,142^{* *}$ \\
Bloco & 4 & $186805,15^{\mathrm{ns}}$ & $474736,94^{\mathrm{ns}}$ & $0,008^{\mathrm{ns}}$ \\
Resíduo & 20 & 429102,41 & 18524118,58 & 0,018 \\
\hline Total & 29 & - & - & - \\
CV $(\%)$ & - & 12,33 & 23,86 & 12,33 \\
Média geral & - & 5,31 & 18,03 & 1,1 \\
\hline
\end{tabular}

${ }^{1}$ Graus de liberdade; **Significativo à nível de $1 \%$; *Significativo à nível de 5\%; ns não significativo pelo teste $\mathrm{F}$.

A PA varia de $3,87 \mathrm{t} \mathrm{ha}^{-1}$ (BRS 9383) a $6,19 \mathrm{t} \mathrm{ha}^{-1}$ (AS 3730), média 5,31 $\mathrm{t} \mathrm{ha}^{-1}$ (Figura $3)$, equivalente a $64,50,103,22$ e 88,57 sacas de $60 \mathrm{~kg}$ por hectare, respectivamente. O rendimento médio nacional na safra
2017/2018 foi $3,38 \mathrm{tha}^{-1}$, igual a 56 sacas de $60 \mathrm{~kg}$ por hectare (CONAB, 2019), logo, nesse trabalho houve um incremento de $36,4 \%$ em relação à média brasileira. 


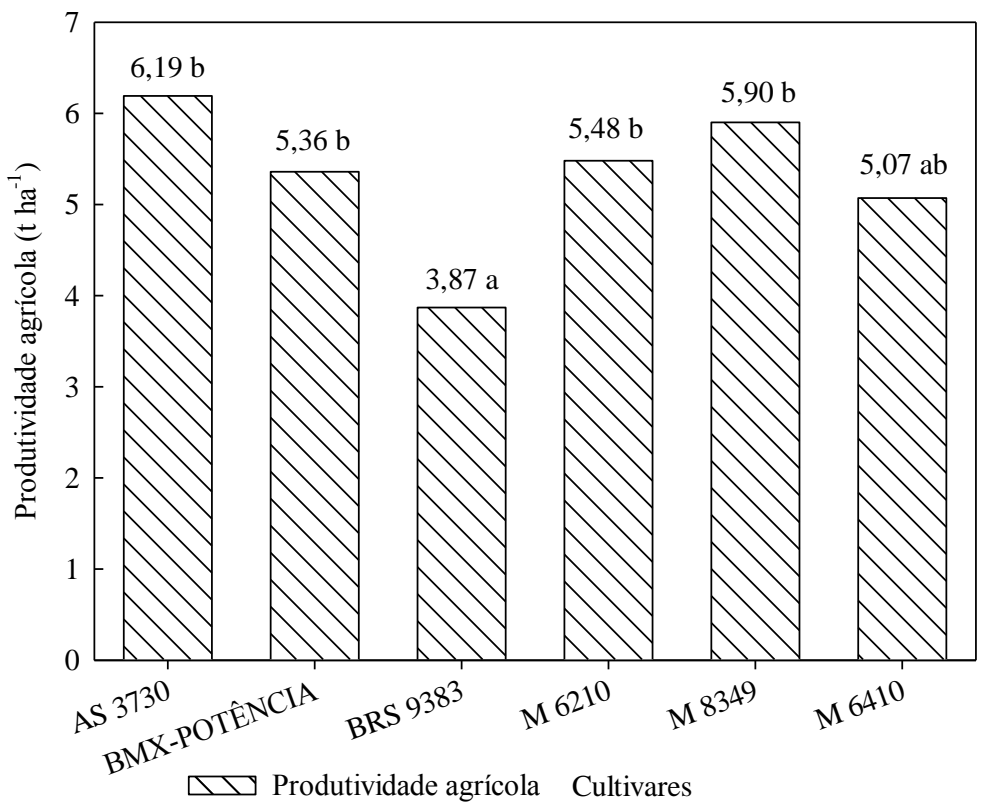

Figura 3. Produtividade agrícola cultivares de soja. Letras indicam diferença significativa pelo teste de Tukey a $P<0,05$, no período de 14 de novembro de 2018 a 03 de abril de 2019, na região de Rio Largo - AL.

A diferença da PA entre as cultivares AS 3730 e BRS 9383 foi de 2,32 $\mathrm{t} \mathrm{ha}^{-1}(38,69$ sacas de $60 \mathrm{~kg}$ por hectare), esse fato pode acontecer devido ao crescimento, desenvolvimento e consequentemente, a produtividade da cultura da soja, uma vez que esses fatores resultam das interações como: cultivar utilizada e fatores decorrentes da sensibilidade ao fotoperíodo e temperatura do ar, que induzem o florescimento e o momento da floração; sensibilidade ao acamamento, reduz a indução da floração e favorece o crescimento vegetativo; sensibilidade a retenção foliar durante o período de formação de vagens e grãos, mantém a planta em crescimento vegetativo em detrimento do crescimento reprodutivo; e a sensibilidade ao excesso ou falta de água (MUNDSTOCK; THOMAS, 2015).
A cultivar BRS 9383 foi a única que apresentou prolongamento do crescimento vegetativo, com colheita realizada no dia 03 de abril de 2019, com o total de 141 dias de ciclo de cultivo, mesmo com características semelhantes a cultivar $M \quad 8349$, as outras cultivares obtiveram média de 125 dias. O alongamento dos entrenós e emissão de ramos acarretou no acamamento da BRS 9383, atrelado com o excessivo crescimento vegetativo e a manutenção da umidade, esses fatores somados, proporcionaram a retenção foliar e formação de poucos órgãos reprodutivos.

$\mathrm{O}$ acúmulo de massa fresca e a diminuição no número de legumes, explica a diferença da produção de MS (Figura 4) e PA entre a cultivar BRS 9383 e as demais. 


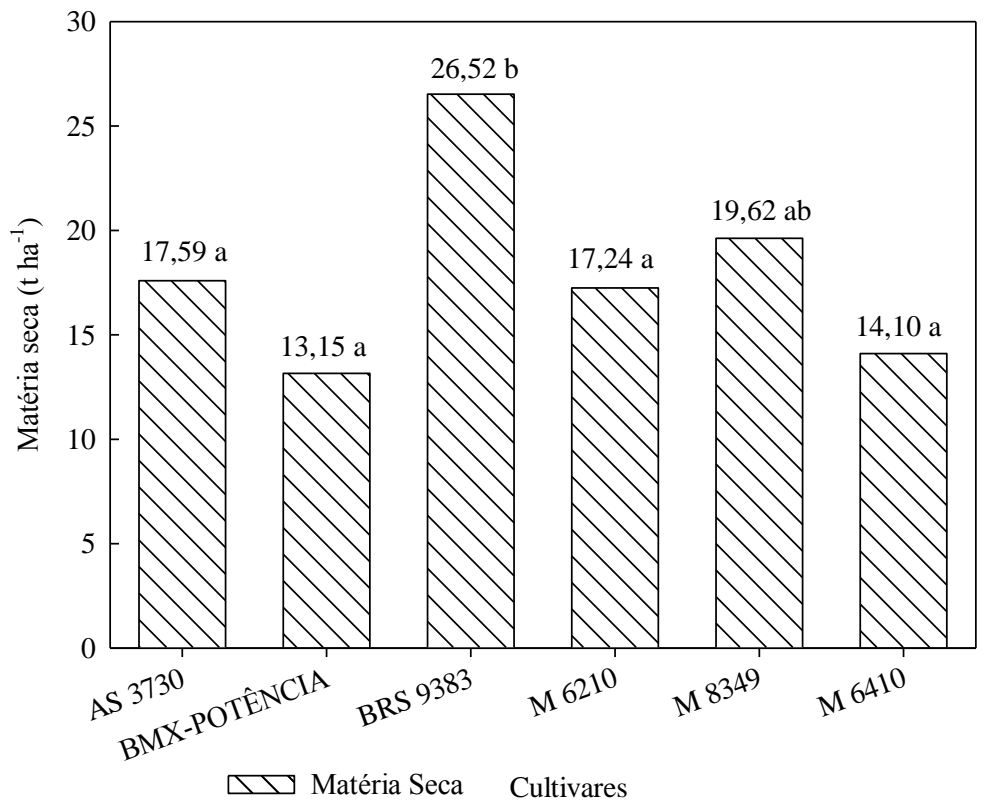

Figura 4. Matéria seca de cultivares de soja. Letras indicam diferença significativa pelo teste de Tukey a $P<0,05$, no período de 14 de novembro de 2018 a 03 de abril de 2019, na região de Rio Largo - AL.

A cultivar AS 3730 e a BRS 9383 tiveram a melhor e a pior EUAG (Figura 5), com 1,3 e $0,80 \mathrm{~kg} \mathrm{~m}^{-3}$, média $1,10 \mathrm{~kg} \mathrm{~m}^{-3}$. Esses valores estão acima dos citados pela EMBRAPA (2011), que é de 0,4 a $0,7 \mathrm{~kg} \mathrm{~m}^{-3}$. Os sistemas de cultivo podem ser modificados para serem mais eficientes no uso da água, seja na seleção de variedades tolerantes a seca ou na seleção de espécies mais responsivas à irrigação e adequadas a cada região climática (HATIFIELD et al., 2001).

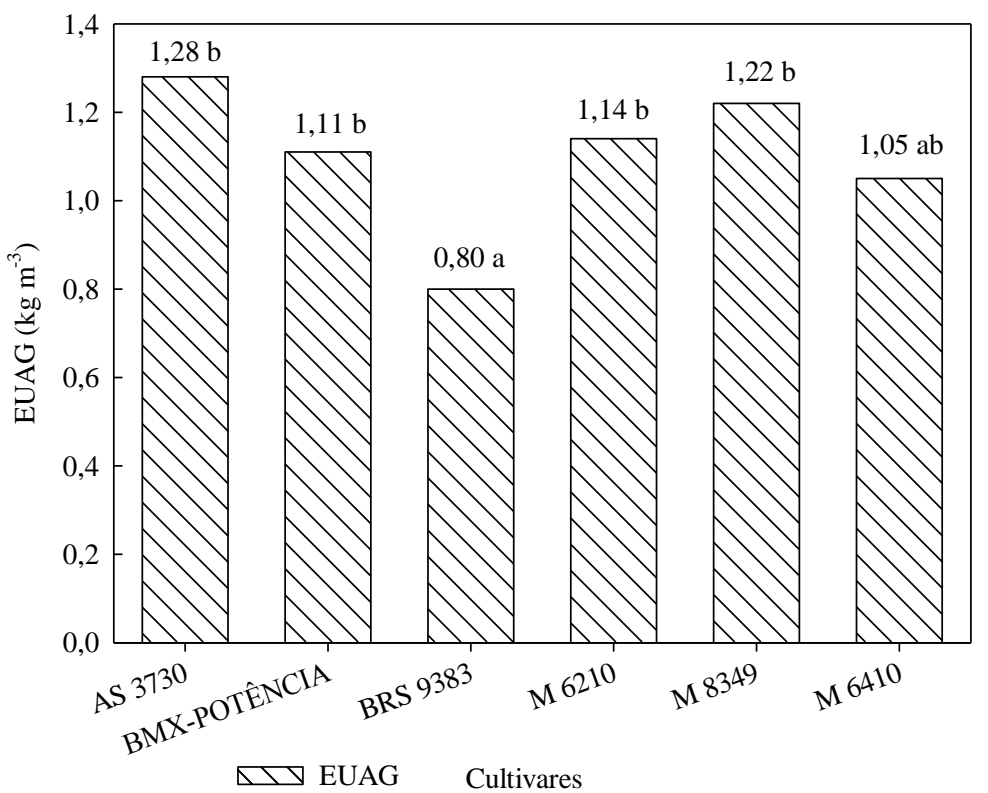

Figura 5. Eficiência no uso da água para produção grãos (EUAG) de cultivares de soja. Letras indicam diferenças significativas pelo teste de Tukey a $P<0,05$, no período de 14 de novembro de 2018 a 03 de abril de 2019, na região de Rio Largo - AL.

\section{CONCLUSÕES}

A evapotranspiração da cultura média é $4,50 \mathrm{~mm}$ por dia, total de $481 \mathrm{~mm}$, em 106 dias, no período de 14 de novembro de 2018 a 28 de fevereiro de 2019. As cultivares AS 3730 e M 8349 foram as que apresentaram melhor desempenho quanto a produtividade de 
grãos e maior no uso da água em relação a produtividade agrícola. Contudo as cultivares BRS 9383 e M 8349 apresentaram maior produção de matéria seca.

Recomenda-se a utilização da cultivar M 8349 com uso de irrigação suplementar, apesar de não diferir estatisticamente das demais, a mesma apresenta uma tendência de ser mais produtiva na região de Rio Largo - AL.

\section{AGRADECIMENTOS}

Ao laboratório de irrigação e agrometeorologia - Prof. José Leonaldo de Souza, pelo suporte e infraestrutura. A Fundação de Amparo à Pesquisa do Estado de Alagoas - FAPEAL e a Coordenação de Aperfeiçoamento de Pessoal de Nível Superior - CAPES pelo fomento de bolsas de pesquisa.

\section{REFERÊNCIAS BIBLIOGRÁFICAS}

AGROFIT. Sistemas de agrotóxicos fitossanitários. Disponível em: $<$ http://extranet.agricultura.gov.br/agrofit_con s/principal_agrofit_cons $>$. Acesso em: 20 out. 2018.

ALLEN, R.G.; PEREIRA, L.S.; RAES, D.; SMITH, M. Crop evapotranspiration: Guidelines for computing crop water requirements. Rome: FAO.1998. 360 p. (FAO. Irrigation end Drainage Paper, 56).

BATTISTI, R.;

P. C. New agroclimatic approach for soybean sowing dates recommendation: A case study. Revista Brasileira de Engenharia Agrícola e Ambiental, v. $18, \quad$ n. $11, \quad$ p. 1149 1156, 2014. https://doi.org/10.1590/18071929/agriambi.v18n11p1149-1156.

CAVALCANTI, F. J. A., coord. Recomendações de adubação para o Estado de Pernambuco: $2^{\mathbf{a}}$ aproximação. 3. ed. IPA, 2008. 212 p.
CHAVARRIA, G.; DURIGON, M. R.; Klein, V. A.; Kleber, H. Restrição fotossintética de plantas de soja sob variação de disponibilidade hídrica. Revista Ciência Rural, v. 45, n. 8, p. 1387-1393, 2015. https://doi.org/10.1590/0103$8478 \mathrm{cr} 20140705$.

COMPANHIA NACIONAL DE ABASTECIMENTO (CONAB). Perspectivas para a Agropecuária Safra 2018/19. CONAB. Brasília. p. 43. 2018. Disponível em: <https://www.conab.gov.br/images/arquivos/o utros/Perspectivas-para-a-agropecuaria-201819.pdf>. Acesso em: 14 jun. 2019.

CRUZ, S. C. S.; SENA-JUNIOR, D. G.; SANTOS, D. M. A.; LUNEZZO, L. O.; MACHADO, C. G. Cultivo de soja sob diferentes densidades de semeadura e arranjos espaciais. Revista de Agricultura Neotropical, v. 3, n. 1, p. 1-6, 2016.

DE REZENDE, P. M.; CARVALHO, E. R.; dos PASSOS, A. M. A.; Martinez, R. A. S. Épocas de semeadura e cultivares de soja na produção de forragem. Bioscience Journal, v. 28, n. 4, 2012.

EMPRESA BRASILEIRA DE PESQUISA AGROPECUÁRIA - EMBRAPA. Tecnologias de produção de soja - Região Central do Brasil 2012 e 2013. Londrina, PR: Embrapa Soja, 2011. 261 p.

FERREIRA JUNIOR, R. A.; SOUZA, J. L. D.; ESCOBEDO, J. F.; TEODORO, I.; LYRA, G. B.; ARAÚJO NETO, R. A. D. Cana-de-açúcar com irrigação por gotejamento em dois espaçamentos entrelinhas de plantio. Revista Brasileira de Engenharia Agrícola e Ambiental, v. 18, n. 8, p. 798-804, 2014 . http://dx.doi.org/10.1590/18071929/agriambi.v18n08p798-804.

FERNANDES, E. J.; TURCO, J. E. P. Evapotranspiração de referência para manejo da irrigação em cultura de soja. Revista Irriga, v. 8, n. 2, p. 132-141, 2003. 
GAVA, R.; FRIZZONE, J. A.; SNYDER, R. L.; JOSE, J. V.; JUNIOR, E. F. F.; PERBONI, A. $O$ estresse hídrico em diferentes fases da cultura da soja. Revista Brasileira de Agricultura Irrigada, v. 9, n. 6, p. 349-359, 2015. DOI: 10.7127/rbai.v9n600368.

GAVA, R.; FRIZZONE, J. A.; SNYDER, R. L.; DE ALMEIDA, B. M.; DE FREITAS, P. S. L.; REZENDE, R. Estratégias de manejo de déficit hídrico na irrigação da cultura da soja. Revista Brasileira de Engenharia de Biossistemas, v. 10, n. 3, p. 305-315, 2016. DOI:

http://dx.doi.org/10.18011/bioeng2016v10n3p 305-315.

HATFIELD, J. L.; SAUER, T. J.; PRUEGER, J. H. Managing soils to achieve greater water use efficiency: a review. Agronomy Journal, v.93, p. 271-280, 2001.

MANOSSO, F.C. A produtividade de soja, trigo e milho e suas relações com a precipitação pluviométrica no município de Apucarana-PR no período de 1968 a 2002. Geografia, v. 14, n. 1, 2005.

MEOTTI, G. V.; BENIN, G.; SILVA, R. R.; BECHE, E.; MUNARO, L. B. Épocas de semeadura e desempenho agronômico de cultivares de soja. Revista Pesquisa Agropecuária Brasileira, v. 47, n. 1, p. 1421, 2012. http://dx.doi.org/10.1590/S0100204X2012000100003.

MORAIS, R. B. G.; LYRA, G. B.; SANTOS, L. R.; CAVALCANTE JÚNIOR, C. A.; CARVALHO, A. L.; LYRA, G. B.; SOUZA, J. L. Crescimento e produtividade de milho em diferentes épocas de plantio, nos Tabuleiros Costeiros de Alagoas. Revista Brasileira de Milho e Sorgo, v. 16, n. 1, p. 109-119, 2017. DOI: $\quad$ https://doi.org/10.18512/19806477/rMS.v16n1p109-119.

MUNDSTOCK, C. M.; THOMAS, A. L. Soja: fatores que afetam o crescimento e rendimento de grãos. Departamento de plantas de lavoura da Universidade Federal do
Rio Grande do Sul. Porto Alegre, RS. 31 p. 2005.

SEDIYAMA, T.; SILVA, F.; BORÉM, A. (Eds.) Soja: do plantio à colheita. 1. ed. Viçosa: Editora UFV, MG, 2015. 333 p.

STÜLP, M.; BRACCINI, A. D. L.; ALBRECHT, L. P.; ÁVILA, M. R.; SCAPIM, C. A.; SCHUSTER, I. Desempenho agronômico de três cultivares de soja em diferentes épocas de semeadura em duas safras. Revista Ciência e Agrotecnologia, v. 33, n. 5, p. 1240-1248, 2009. http://dx.doi.org/10.1590/S141370542009000500006 .

RUVIARO, C.; DORNELES, J.; Silva, A. M.; BEN, C. Comportamento da soja submetida a diferentes regimes hídricos e viabilidade da irrigação suplementar na região do Vale do Jaguari-RS. Revista Perspectiva, v. 35 , n. 131, p. 79-90, 2011.

TEODORO, I. Avaliação da evapotranspiração e desenvolvimento da cultura do milho irrigação na região de Rio Largo - AL. 2003 Dissertação (Mestrado em Meteorologia). UNIVERSIDADE FEDERAL DE ALAGOAS.

TRENTIN, R.; HELDWEIN, A. B.; STRECK, N. A.; TRENTIN, G.; SILVA, J. C. D. Subperíodos fenológicos e ciclo da soja conforme grupos de maturidade e datas de semeadura. Revista Pesquisa Agropecuária Brasileira, v. 48, n. 7, p. 703-713, 2013. https://doi.org/10.1590/S0100-

$204 X 2013000700002$.

ZANON, A. J.; WINCK, J. E. M.; STRECK, N. A.; ROCHA, T. S. M. D.; CERA, J. C.; RICHTER, G. L.; LAGO, I.; SANTOS, P. M.; MACIEL, L. R.; GUEDES, J. V. C.; MARCHESAN, E. Desenvolvimento de cultivares de soja em função do grupo de maturação e tipo de crescimento em terras altas e terras baixas. Revista Bragantia, v. 74, n. $4, \quad$ p. 400-411, 2015. https://doi.org/10.1590/1678-4499.0043. 